Check for updates

Cite this: RSC Adv., 2017, 7, 42296

Received 1st August 2017

Accepted 25th August 2017

DOI: $10.1039 / c 7 r a 08464 a$

rsc.li/rsc-advances

\title{
High-performance anionic waterborne polyurethane/Ag nanocomposites with excellent antibacterial property via in situ synthesis of $\mathrm{Ag}$ nanoparticles
}

\author{
Zhen Zhong, Shun Luo, Kai Yang, Xiaojian Wu and Tianbin Ren (ID*
}

\begin{abstract}
Anionic waterborne polyurethane (WPU)/inorganic nanoparticle composites have attracted growing interest due to their outstanding properties. In our work, high-performance anionic WPU/Ag nanocomposites with excellent antibacterial property were successfully prepared by an in situ method, where carboxylate-functionalized WPUs served as stabilizers for the synthesis of AgNPs. The chemical structure of the prepared WPU and WPU/Ag nanocomposite was characterized via FTIR spectroscopy and UV-vis spectroscopy, while TEM, SEM and XRD were also used to confirm the formation of AgNPs in the WPU matrix. The results demonstrated that the formed AgNPs exhibited a spherical shape and were evenly distributed in the WPU matrix. The size of AgNPs ranged from 5 to $50 \mathrm{~nm}$ depending on the amount of added $\mathrm{AgNO}_{3}$ in WPU dispersions. More importantly, incorporation of AgNPs in the WPU matrix was demonstrated to significantly improve the thermal stability, mechanical performance and water resistance property of the WPU films. Furthermore, the presence of AgNPs provided the nanocomposite films with excellent antibacterial behavior against $E$. coli. Given these advantages, our obtained WPU/Ag nanocomposites could be suitable for a broad range of commercial applications.
\end{abstract}

\section{Introduction}

As superior alternatives to conventional solvent-based polyurethanes, waterborne polyurethanes (WPUs) have attracted growing interest due to their low evaporation of volatile organic compounds (VOC), environmentally friendly nature and desirable physical and chemical properties. ${ }^{1-3}$ Benefiting from these attractive attributes, WPUs have been widely used in coatings, adhesives, leather finishing, paper and textile industries.4-9 However, owing to the linear structure of WPUs and the presence of hydrophilic ionic groups or water-soluble segments in their backbone, WPUs tend to exhibit poor mechanical properties, thermal stability and solvent resistance, remaining to be the major challenge for their commercial applications.

To solve this dilemma, various nanomaterials have been blended into WPUs matrices as reinforcement fillers for improving the properties of WPUs. ${ }^{10-12}$ Among these nanomaterials, silver nanoparticles (AgNPs), as one of the most fascinating noble metal nanoparticles, display excellent broadspectrum antimicrobial properties. ${ }^{13,14}$ The previous studies have demonstrated that incorporation of AgNPs into WPUs could

Institute of Nano- and Bio-polymeric Materials, Key Laboratory of Advanced Civil Engineering, Materials of Ministry of Education, School of Material Science and Engineering, Tongji University, Shanghai 201804, China.E-mail: rentianbin@yeah.net not only enhance the mechanical properties and thermal stability of WPUs significantly, but also endow WPUs with excellent antibacterial properties. ${ }^{15}$ The most common strategy for preparation of AgNPs-blended WPUs nanocomposites involves two steps including the synthesis of AgNPs first and then blending them into WPUs. ${ }^{16,17}$ In this case, however, the inevitable aggregation of AgNPs occurs during the blending process, leading to the inhomogeneous distribution of AgNPs in WPUs as well as reducing antibacterial properties of the prepared WPUs/Ag nanocomposites. In addition, it is still challenging to prepare WPUs/Ag nanocomposites in large-scale for real applications, since the synthesis and purification processes of AgNPs are relatively complex and not time-efficient or cost-effective.

Alternatively, in situ synthesis of AgNPs in WPUs matrix is considered as a promising method for preparation of WPUs/Ag nanocomposites, where WPUs matrix used as a stabilizing agent could effectively prevent AgNPs aggregation after solvent removal. For example, Wattanodorn et al. prepared WPUs/Ag nanocomposites by in situ reduction of silver ions using $\mathrm{NaBH}_{4}$ in the commercial anionic WPU and the nanocomposites demonstrated not only excellent antibacterial efficiency of 99.99\% for Escherichia coli and 53.97\% for Staphylococcus aureus but also enhanced mechanical properties. ${ }^{\mathbf{1 5}}$

In this study, anionic WPU with carboxylate-functional group was designed and synthesized via addition of bis(hydroxymethyl) 

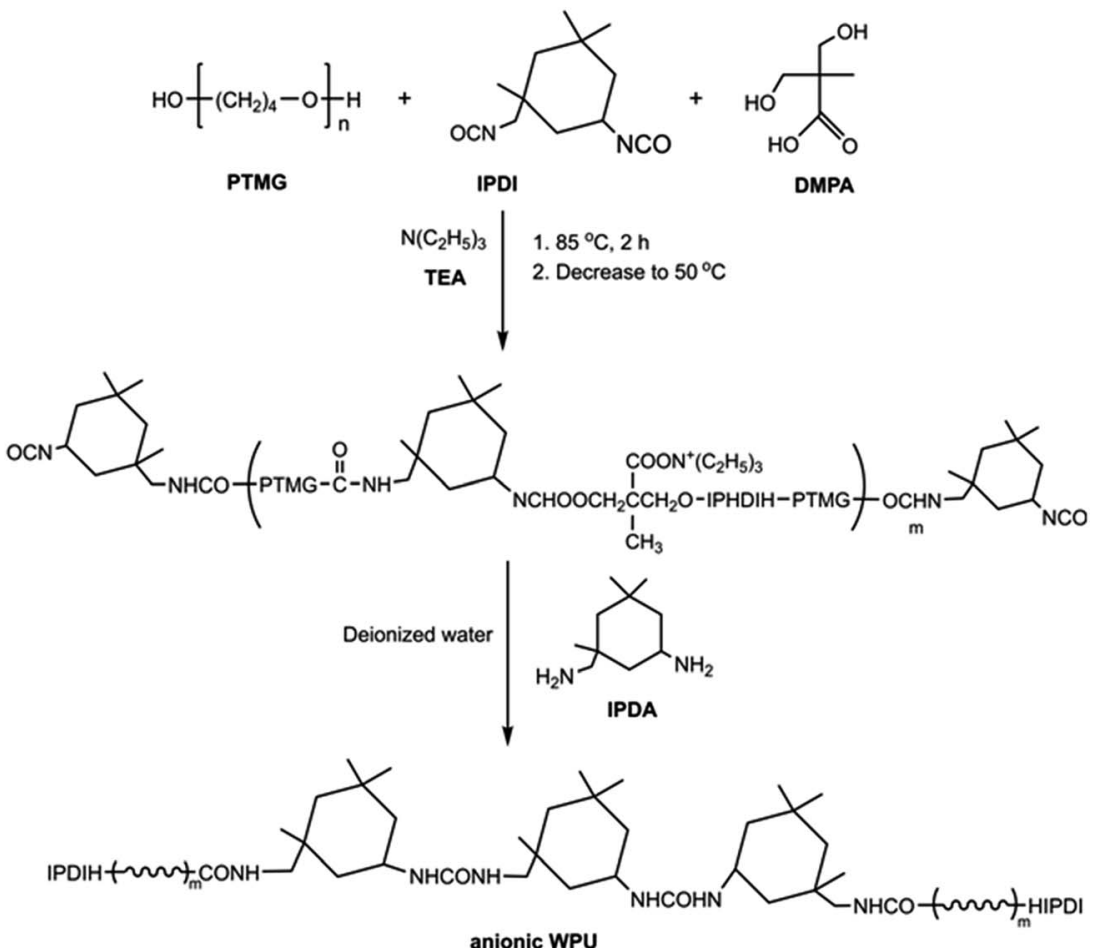

Fig. 1 Synthesis process for an anionic WPU dispersion

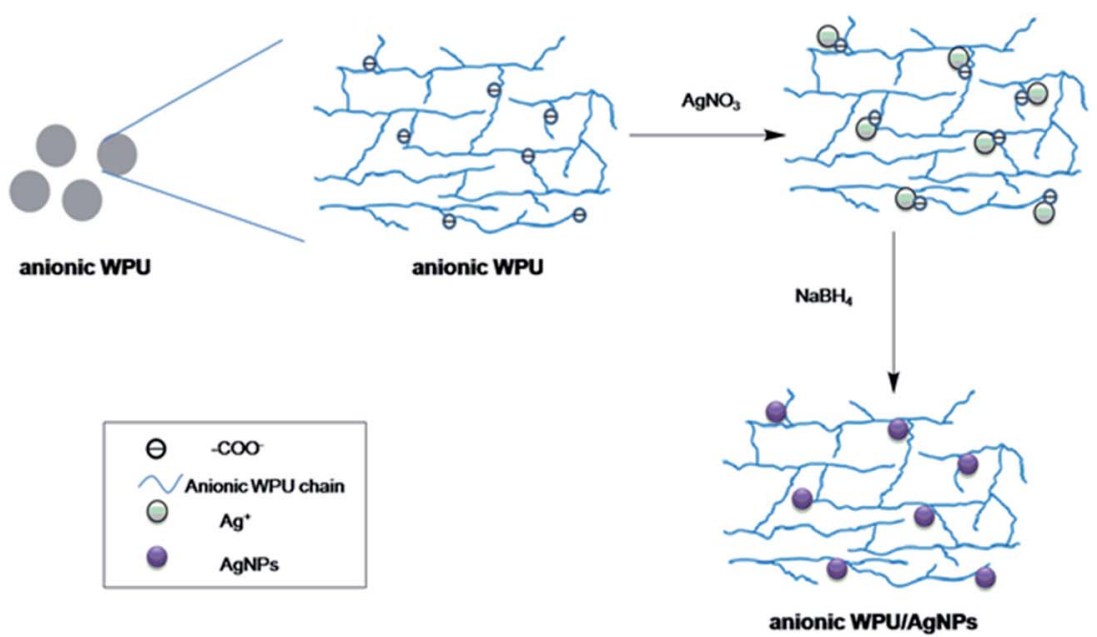

Fig. 2 Schematic diagram for preparing anionic WPU/Ag nanocomposites.

propionic acid (DMPA) during the preparation process of WPU. The tailor-made WPU could serve as a stabilizer to in situ form AgNPs and prepare WPUs/Ag nanocomposites, as illustrated in Fig. 1 and 2. The chemical structure of WPUs and the formation of AgNPs were characterized via Fourier transform infrared spectrophotometer (FTIR), UV-vis absorption spectrophotometer, $\mathrm{X}$-ray diffractometer (XRD) and transmission electron microscope (TEM), respectively. The effects of the incorporated AgNPs on thermal stabilities, water resistance, mechanical performance and antibacterial activity of the fabricated WPU/Ag nanocomposite films were also investigated.

\section{Experimental}

\section{Materials}

Polytetramethylene ether glycol (PTMG, $M_{\mathrm{n}}=2000$ ) was provided by Jining Chemical (China). Isophorone diisocyanate (IPDI) was obtained from Covestro (Germany). Dibutyltin dilaurate (DBTDL), isophoronediamine (IPDA), bis(hydroxymethyl)propionic acid (DMPA), triethylamine (TEA) and silver nitrate $\left(\mathrm{AgNO}_{3}\right)$ were obtained from Sinopharm Chemical Reagent Shanghai Co., Ltd., China and used as received. Sodium borohydride $\left(\mathrm{NaBH}_{4}\right)$ was purchased from Sigma- 
Table 1 Formulas of the anionic WPU and anionic WPU/Ag nanocomposites

\begin{tabular}{|c|c|c|c|c|c|c|}
\hline Designation & PTMG (mol) & IPDI (mol) & DMPA (mol) & TEA (mol) & IPDA (mol) & $\mathrm{AgNO}_{3}(\mathrm{~mol})$ \\
\hline WPU & 1.0 & 3.0 & 1.2 & 1.2 & 0.4 & 0 \\
\hline WPU/Ag-1 & 1.0 & 3.0 & 1.2 & 1.2 & 0.4 & 0.075 \\
\hline WPU/Ag-3 & 1.0 & 3.0 & 1.2 & 1.2 & 0.4 & 0.3 \\
\hline WPU/Ag-4 & 1.0 & 3.0 & 1.2 & 1.2 & 0.4 & 0.6 \\
\hline
\end{tabular}

Aldrich (St. Louis, MO, USA). Escherichia coli (ATCC 25922) was obtained from Nanjing Bianzhen Biological Technology (China). Phosphate buffer saline solution was provided by Shanghai Meilian Biological Technology (China).

\section{Synthesis of an anionic WPUs dispersion}

PTMG (100 g, $0.05 \mathrm{~mol}$ ) was placed in a $500 \mathrm{ml}$ four-necked flask equipped with a magnetic stirrer, reflux condenser, temperature controller and nitrogen gas inlet, and was degassed in vacuum at $90{ }^{\circ} \mathrm{C}$ for $30 \mathrm{~min}$ and it was allowed to cool to $50{ }^{\circ} \mathrm{C}$ under moderate stirring (175-200 rpm). Then, IPDI (33 g, $0.15 \mathrm{~mol})$ was added into the flask. The mixture was stirred (175-200 rpm) for $2 \mathrm{~h}$ at $85^{\circ} \mathrm{C}$ under nitrogen atmosphere. Then DMPA (7.98 g, $0.06 \mathrm{~mol}$ ) was added to the reaction flask and the mixture was cooled to $80{ }^{\circ} \mathrm{C}$, followed by the addition of DBTDL and stirring for additional $3 \mathrm{~h}$. After that, the mixture was cooled to $50{ }^{\circ} \mathrm{C}$ with the addition of TEA ( $6.02 \mathrm{~g}, 0.06 \mathrm{~mol})$. Deionized water was introduced into the reaction mixture with vigorous stirring (1400-1500 rpm) for $30 \mathrm{~min}$. IPDA $(3.5 \mathrm{~g}, 0.02 \mathrm{~mol})$ was finally added to complete the synthesis. The resulting product was a stable anionic WPU dispersion with a solid content of about $30 \mathrm{wt} \%$. The synthesis process for an anionic WPU dispersion is shown in Fig. 1.

\section{Preparation of anionic WPU/Ag nanoparticle composites}

The anionic WPU dispersion was adjusted to $15 \mathrm{wt} \%$ solution by deionized water. $\mathrm{AgNO}_{3}\left(0.1 \mathrm{~mol} \mathrm{l}^{-1}\right)$ aqueous solution was prepared by dissolving $\mathrm{AgNO}_{3}$ in deionized water and then added into the anionic WPU dispersion. The mixture was stirred at room temperature for $30 \mathrm{~min}$, followed by addition of $\mathrm{NaBH}_{4}$ for another $2 \mathrm{~h}$. The $\mathrm{AgNO}_{3}$ to $\mathrm{NaBH}_{4}$ mole ratio was 1/2. Anionic WPU/Ag nanoparticle composites were prepared by in situ chemical reduction. A series of nanocomposites were prepared with different content of $\mathrm{AgNO}_{3}$. The schematic diagram for nanocomposites was illustrated in Fig. 2. And the formulas of anionic WPU and anionic WPU/Ag nanocomposites were listed in Table 1.

\section{Preparation of films}

The anionic WPU and anionic WPU/Ag nanocomposites films (typically about $0.5 \mathrm{~mm}$ thick) were prepared by casting dispersion onto a Teflon plates and dried at room temperature for $24 \mathrm{~h}$, followed by continuous drying at $60{ }^{\circ} \mathrm{C}$ under vacuum to constant weight. The samples were stored in the drying cabinet for the following tests.

\section{Characterization of the anionic WPU and WPU/Ag nanocomposites}

The FTIR spectra were recorded on a Nicolet 6700 Fourier transform infrared spectrometer in ATR mode (Thermo Fisher, USA). UV-visible spectra of the samples were measured by UV-vis absorption spectrophotometer (HITACHI U-1800, Japan). Transmission electron microscopy (TEM) was performed with a JEOL JEM-2000 microscope operating at $200 \mathrm{kV}$. To prepared the sample, one droplet of a diluted dispersion ( $0.5 \mathrm{wt} \%)$ solution was dripped onto a 200-mesh carbon-coated copper grid and dried at room temperature. X-ray diffraction (XRD) measurements were performed on a D/max-IIIA. X-ray diffractometer (Rigaku Denki, Tokyo, Japan) used $\mathrm{Cu} \mathrm{K} \alpha$ radiation $(\lambda=0.154$ $\mathrm{nm}$ ) at $35 \mathrm{kV}$ and $30 \mathrm{~mA}$ with a scan rate of $4^{\circ} \mathrm{min}^{-1}$. The film morphology was observed by scanning electron microscopy (SEM) (FEI, USA) and the distribution of $\mathrm{Ag}$ element on film surface was determined by using BrukerX Flash Detector 6/30 energy dispersive X-ray spectroscopy (EDX) under $15 \mathrm{keV}$.

\section{Thermal analysis, mechanical testing and water resistance properties testing}

The thermal stabilities of the anionic WPU and WPU/Ag nanocomposite films were recorded on TA Instruments Q500 (New Castle, DE, USA) under a nitrogen purge. Film samples of 4 to $6 \mathrm{mg}$ were placed on a platinum sample pan and heated from 20 to $800{ }^{\circ} \mathrm{C}$ with a scanning rate of $20^{\circ} \mathrm{C} \mathrm{min}^{-1}$. And the thermal properties of the samples were also measured using differential scanning calorimetry (DSC) (NETZSCH, Germany) at a heating/ cooling rate of $10{ }^{\circ} \mathrm{C} \min ^{-1}$ between $-80{ }^{\circ} \mathrm{C}$ and $200{ }^{\circ} \mathrm{C}$ under nitrogen atmosphere. Mechanical testing was carried out on a tensile tester (MTS CMT4000, China) at room temperature

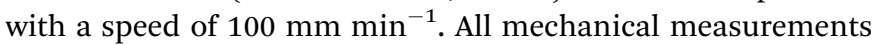
were carried out with an average of three runs. All mechanical testing specimens were molded into a dumbbell type whose dimension in the parallel part was $30 \mathrm{~mm}$ in length. The dimension of the samples was $70 \mathrm{~mm} \times 5 \mathrm{~mm} \times 2 \mathrm{~mm}$. The water resistance properties of the anionic WPU and the anionic WPU/AgNPs films were characterized by the swelling degree. To evaluate the swelling degree, anionic WPU and WPU/Ag film samples with a dimension of $3 \times 5 \mathrm{~cm}^{2}$ was placed in a sealed conical flask containing $100 \mathrm{ml}$ of $20 \mathrm{wt} \%$ aqueous ethanol solution for $24 \mathrm{~h}$. The weight of the film before and after immersion with $20 \mathrm{wt} \%$ aqueous ethanol solution was measured, and the swelling degree was calculated according to the following equation: 


$$
\text { Swelling degree }=\frac{W_{\mathrm{w}}-W_{\mathrm{d}}}{W_{\mathrm{d}}} \times 100 \%
$$

where $W_{\mathrm{d}}$ is the weight of the dried film and $W_{\mathrm{w}}$ is the weight of the swollen film.

\section{Antibacterial activity test}

To quantitatively assess the antibacterial behaviors of the obtained anionic WPU and anionic WPU/Ag nanocomposite films, a shake flask method was used in this study following the test standard of ASTM E-2149 (2013). ${ }^{18}$ Typically, the film samples with $5 \times 5 \mathrm{~cm}^{2}$ in size were used in this method. Nutrient broth was used as a growing medium for Gram-negative Escherichia coli and phosphate buffer saline solution was chosen as a testing medium. In this work, the bacteria were cultivated in $5 \mathrm{ml}$ of nutrient broth at $37{ }^{\circ} \mathrm{C}$ for $24 \mathrm{~h}$. The film samples and initial suspended bacteria of $10^{6} \mathrm{cfu} \mathrm{m}^{-1}$ were placed into a $250 \mathrm{ml}$ flask containing $70 \mathrm{ml}$ of phosphate buffer saline. The flask was shaken on a reciprocal shaker at a speed of $220 \mathrm{rpm}$ at $37{ }^{\circ} \mathrm{C}$ for $1 \mathrm{~h}$. Plate count agar technique was then used for quantitative assessment of testing specimens. A 10-fold serial dilution technique was used for ensuring a reliable accounting of the bacteria colonies. Then $0.5 \mathrm{ml}$ of bacterial suspension after shaking was placed over the agar into sterilized Petri dishes. Then bacteria colonies were counted after incubation at $37^{\circ} \mathrm{C}$ for $48 \mathrm{~h}$. The antibacterial ratio was calculated as follows:

$$
\text { Antibacterial ratio }=\frac{N_{0}-N}{N_{0}} \times 100 \%
$$

where $N_{0}$ is the mean number of bacteria on the anionic WPU film, and $N$ is the mean number of bacteria on the anionic WPU/ $\mathrm{Ag}$ nanocomposite film. The antibacterial activity test of each sample was repeated three times.

\section{Results and discussion}

\section{The synthesis and characterization of anionic WPU and WPU/ Ag nanocomposites}

The synthesis processes of anionic WPU and WPU/Ag nanocomposites with different Ag content were illustrated in Fig. 1 and 2, and the chemical structures of the prepared anionic WPU and WPU/Ag nanocomposites were characterized with FTIR. As presented in Fig. 3, both WPU and WPU/Ag nanocomposites showed typical absorption peaks of polyurethane at $2858 \mathrm{~cm}^{-1}$, $2939 \mathrm{~cm}^{-1}$ (associated to the symmetric and asymmetric stretching modes of $\left.-\mathrm{CH}_{2}\right),{ }^{19}$ and $1668 \mathrm{~cm}^{-1}(\mathrm{C}=\mathrm{O}$ stretching of urethane). The other characteristic peak at $3380 \mathrm{~cm}^{-1}$ was attributed to the $\mathrm{N}-\mathrm{H}$ stretching vibration, $1537 \mathrm{~cm}^{-1}$ attributed to the $\mathrm{N}-\mathrm{H}$ deformation vibration, $1450 \mathrm{~cm}^{-1}$ attributed to the symmetric stretching vibration of $-\mathrm{COO}^{-}$, and $1390 \mathrm{~cm}^{-1}$ and $1105 \mathrm{~cm}^{-1}$ attributed to symmetric bending vibration of $-\mathrm{CH}_{3}$ and $\mathrm{C}-\mathrm{O}-\mathrm{C}$ stretching vibration, respectively. The peak of $-\mathrm{NCO}$ group of IPDI at around $2270 \mathrm{~cm}^{-1}$ was not observed, indicating that -NCO groups were completely reacted. After in situ formation of AgNPs, an obvious change of the peaks occurred in the range of $1254 \mathrm{~cm}^{-1}$ to $1450 \mathrm{~cm}^{-1}$. The WPU/Ag-4 showed one strong band at $1390 \mathrm{~cm}^{-1}$ overlapping with a weak band at
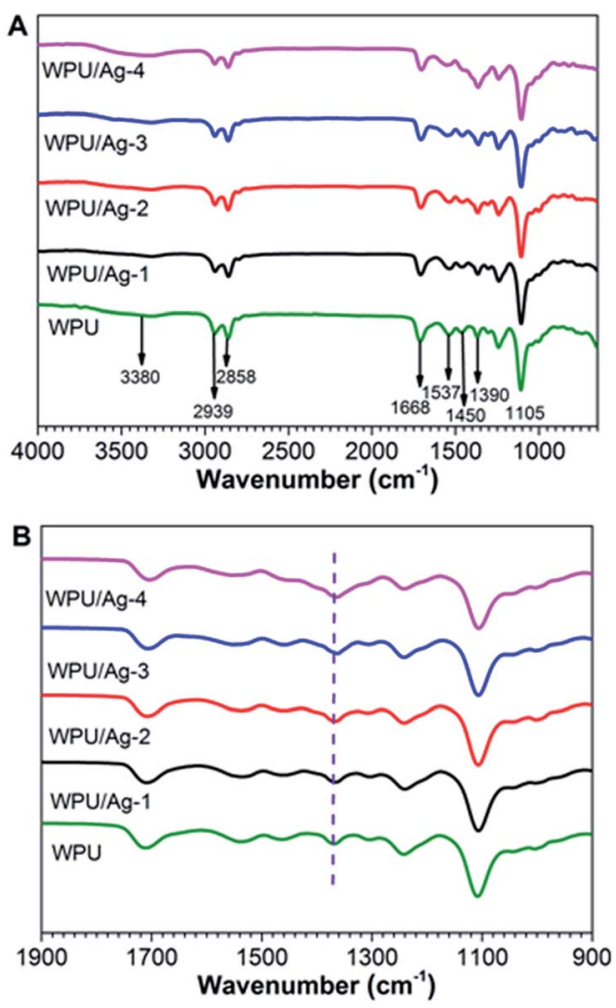

Fig. 3 FTIR spectra of the anionic WPU and WPU/Ag nanocomposites.

$1450 \mathrm{~cm}^{-1}$, while the pristine WPU displayed a relatively weak band at $1390 \mathrm{~cm}^{-1}$ and a relatively weak band at $1450 \mathrm{~cm}^{-1}$. These changes were probably due to the interaction between AgNPs and $-\mathrm{COO}^{-}$and -NH groups, and the hydrogen bonding present in the nanocomposites. ${ }^{20}$

The UV-vis absorption spectroscopy was used to determine the formation of AgNPs in anionic WPUs by tracking the characteristic absorbance peaks of the surface plasmon resonance of AgNPs at around $415 \mathrm{~nm}$, because AgNPs are known to exhibit intense plasmon absorption bands in such visible region. ${ }^{21}$ As shown in Fig. 4A, prominent absorption peaks centered $415 \mathrm{~nm}$ were observed confirming the formation of AgNPs in WPUs dispersion solution. Furthermore, UV-vis spectra of WPU/Ag-4 contained a relatively narrow sharp band around $370 \mathrm{~nm}$. Similar bands have been previously attributed to magic-sized silver clusters of different sizes. ${ }^{22}$ The band may also result from another phenomenon such as multipole plasmon resonances observed for larger and less spherical silver nanocrystals. ${ }^{23}$ Besides, with the increase of the concentration of silver ions in anionic WPUs dispersion solution, the color of the obtained anionic WPUs/Ag nanocomposite dispersion solutions after reduction turned from transparent to dark brown. The absorption maxima of the anionic WPUs/Ag nanocomposites dispersion solution exhibited a shift to longer wavelength, indicating the larger size of the formed AgNPs under high concentration of silver ions. All of these suggest that the concentration of silver ions may affect the size and shape of formed AgNPs. Further, the stability of the formed AgNPs in WPUs dispersion solutions was investigated. As shown in 

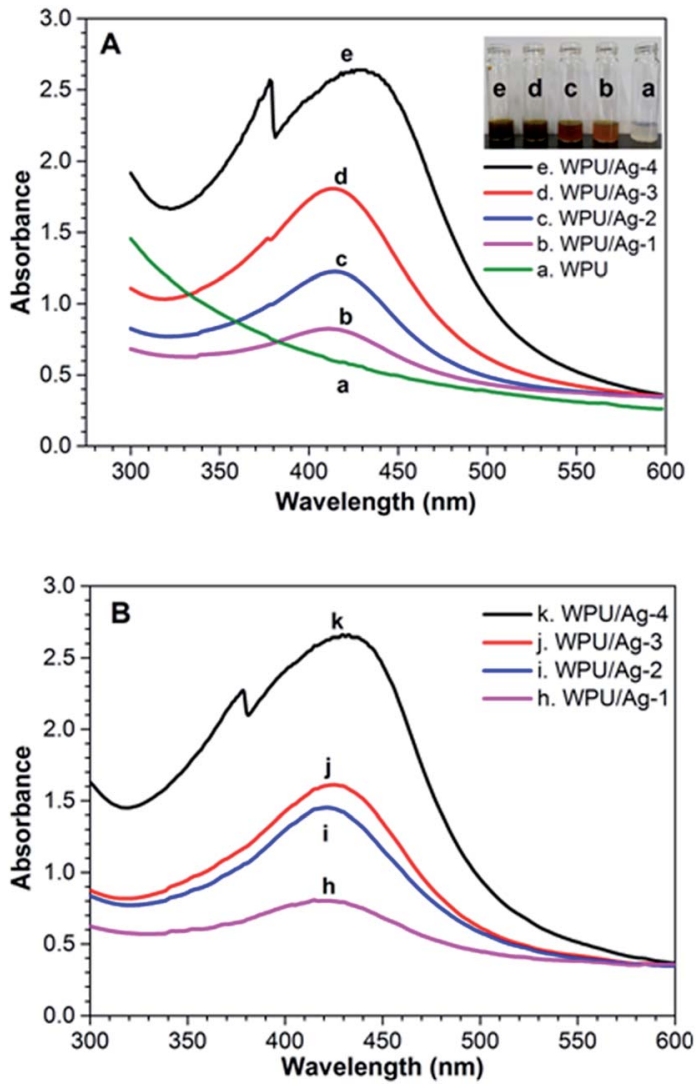

Fig. 4 (A) UV-vis spectra of WPU (a), WPU/Ag-1 (b), WPU/Ag-2 (c), WPU/Ag-3 (d) and WPU/Ag-4 (e) (insert is the photographs of WPU (a), WPU/Ag-1 (b), WPU/Ag-2 (c), WPU/Ag-3 (d) and WPU/Ag-4 solution (e); (B) UV-vis spectra of WPU/Ag-1 (h), WPU/Ag-2 (i), WPU/Ag-3 (j) and WPU/Ag-4 (k)) after three months.

Fig. 4B, the absorption peaks of anionic WPUs/Ag nanocomposites after storing for three months did not show an obvious change compared with the freshly prepared anionic
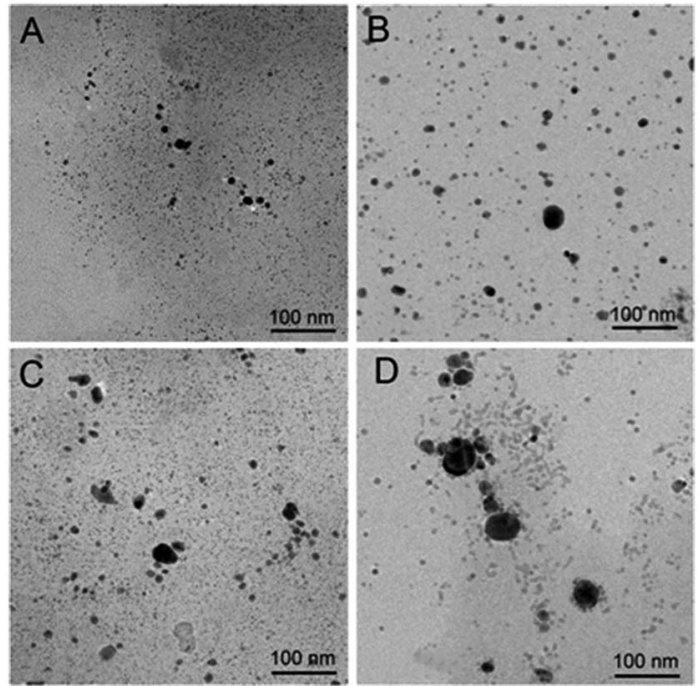

Fig. 5 TEM images of AgNPs encapsulated by WPU (A) WPU/Ag-1, (B) WPU/Ag-2, (C) WPU/Ag-3, (D) WPU/Ag-4.
WPUs/Ag nanocomposites, demonstrating few aggregations of AgNPs and excellent stability of the WPUs/Ag nanocomposites.

TEM was also exploited to observe the size and distribution of the formed AgNPs in WPU matrix with different silver ions concentration. As shown in Fig. 5, most of the formed AgNPs exhibited a spherical shape with the diameter in the range of 5-50 nm. The AgNPs were dispersed uniformly in WPU matrix under low concentration (Fig. 5A-C). Small aggregations in the WPU matrix appeared when the concentration of silver ions was increased (Fig. 5D). It could also be seen that AgNPs with small size and narrow size distribution were formed at low concentration of silver ions (Fig. 5A-C). The size and size distribution of the formed AgNPs showed a significant increase with the concentration of silver ions increasing, generally consistent with the findings of UV-vis absorption.

Dispersion of metal nanoparticle in polymer matrix is very important to improve the properties of polymer/metal nanoparticle composites. In order to investigate the dispersion of AgNPs in WPU matrix, SEM-EDX was further used to observe the morphology of WPU/Ag-1 nanocomposite and determine the distribution of $\mathrm{Ag}$ element in the nanocomposite surface. Fig. 6A showed that there were no aggregated nanoparticles on the surface of WPU/Ag-1 nanocomposite, indicating the homogeneous distribution of AgNPs in WPU matrix. The distribution of sliver element was mapped on the nanocomposite surface using EDX to be uniform across the scanned area (red spots), shown in Fig. 6B. All of results confirmed that uniform AgNPs was successfully synthesized and exhibited even distribution in WPU matrix.
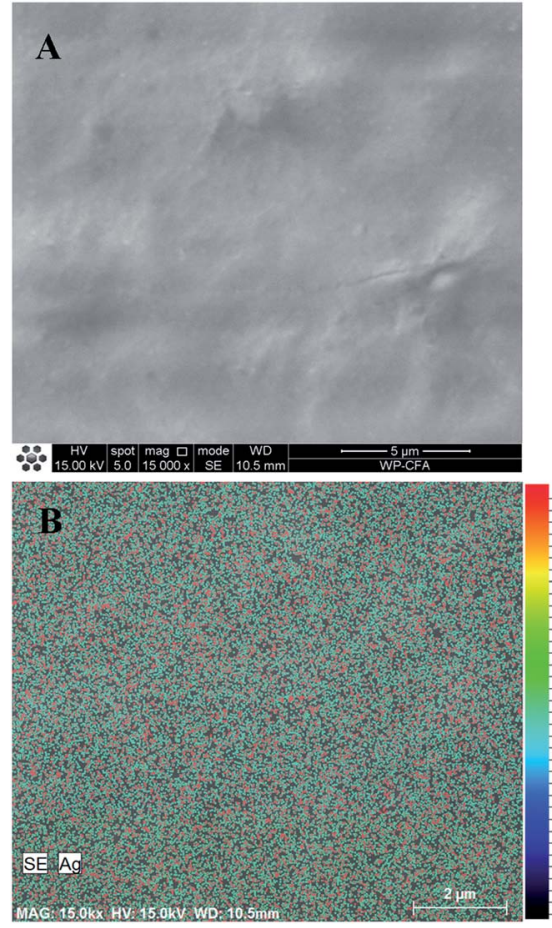

Fig. 6 SEM image of WPU/Ag-1 nanocomposite (A) and the distribution of silver $(\mathrm{Ag})$ element on the same area of WPU/Ag-1 nanocomposite (B). 


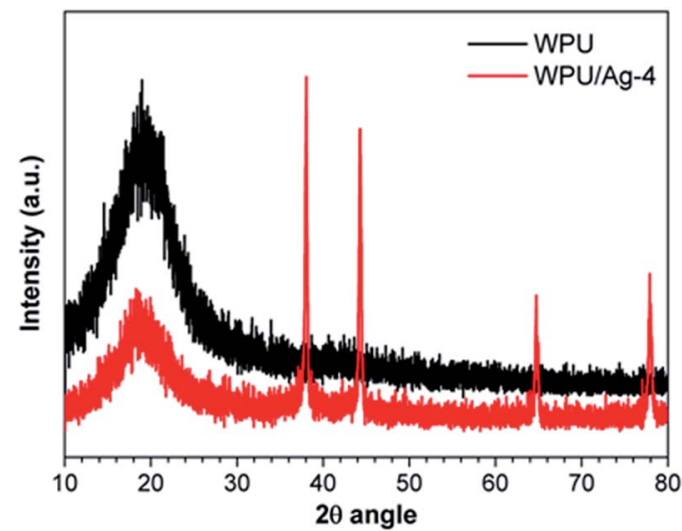

Fig. 7 XRD spectra of WPU and WPU/Ag-4 nanocomposite.

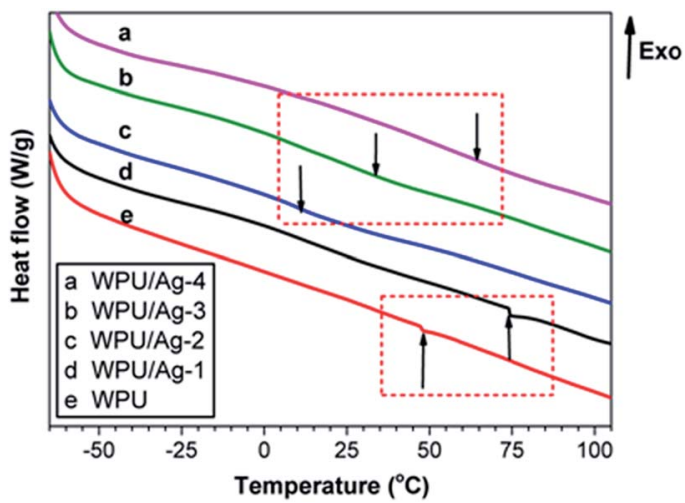

Fig. 8 DSC curves of WPU and WPU/AgNPs films.

XRD spectra of WPU and WPU/Ag-4 nanocomposite were shown in Fig. 7. In the spectrum of WPU, there was no obvious diffraction peak and only a scattering peak appears at around $20^{\circ}$, which was probably due to the amorphous structure, small crystalline structure or diffraction from large crystals. ${ }^{24}$ By contrast, the WPU/Ag-4 nanocomposite appeared to possess unique peaks at $38^{\circ}, 44^{\circ}, 64^{\circ}$ and $77^{\circ}$, corresponding to the (111), (200), (220) and (311) planes of the face-centered cubic silver nanoparticles, respectively. ${ }^{25}$

\section{Thermal stabilities of WPU and WPU/Ag nanocomposite films}

In order to investigate the influences of AgNPs incorporation on the thermal stabilities of the anionic WPU/Ag nanocomposite films, DSC and TGA analyses were performed. As shown in Fig. 8, all the samples showed the glass transitions temperature $\left(T_{\mathrm{g}} \mathrm{s}\right)$ of soft segment being around $-55^{\circ} \mathrm{C}$ corresponding to the soft segment of PTMG. ${ }^{26}$ For the pristine WPU film, an apparent melting temperature $\left(T_{\mathrm{m}}\right)$ peak of PTMG soft segment was observed, indicating little crystallinity of the pristine WPU, which is consistent with XRD results. The peak of WPU/Ag-1 film exhibited an increase from $46{ }^{\circ} \mathrm{C}$ to $72{ }^{\circ} \mathrm{C}$ after incorporation of AgNPs, indicating the incorporated AgNPs at low added amount of $\mathrm{AgNO}_{3}$ could facilitate the crystallization of WPU. However, the melting temperature $\left(T_{\mathrm{m}}\right)$ peak disappeared with
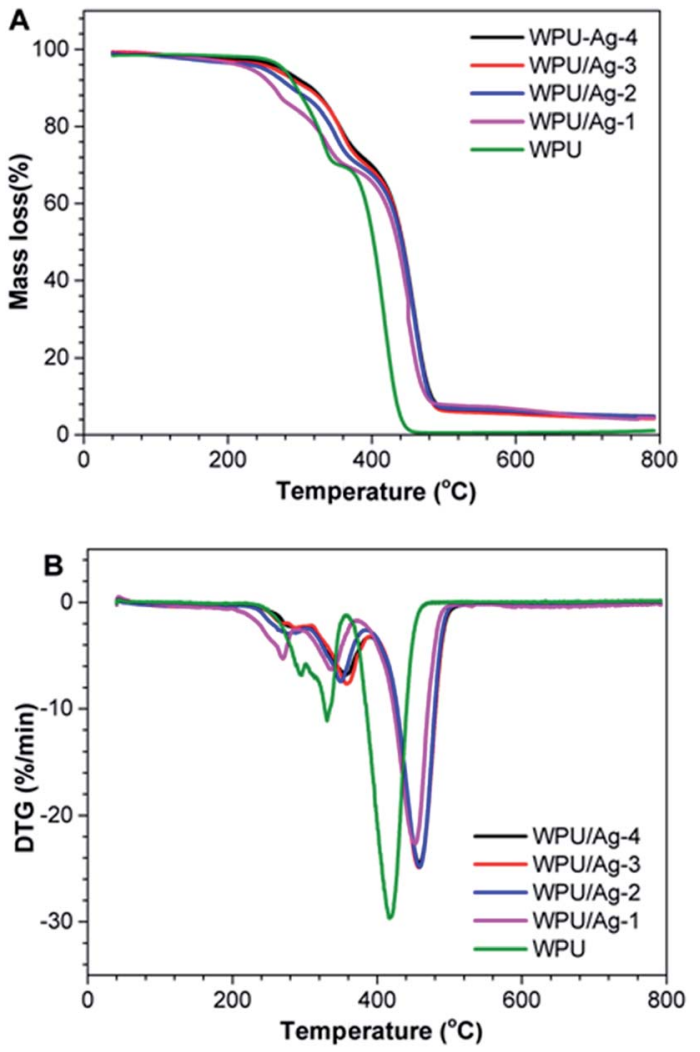

Fig. 9 TG and DTG curves of the WPU and WPU/Ag nanocomposite films.

the added amount of $\mathrm{AgNO}_{3}$ in WPU dispersions further increasing, demonstrating that the crystallization of the WPU films was disturbed. In addition, $T_{\mathrm{g}}$ of hard segment for WPU/Ag-2, WPU/Ag-3 and WPU/Ag-4 films increased from $10{ }^{\circ} \mathrm{C}$ to $62{ }^{\circ} \mathrm{C}$, suggesting the formed large amounts of AgNPs in WPU matrix served as hard segment.

The thermal decomposition behaviors of the pristine WPU and WPU/Ag nanocomposite films were presented in Fig. 9 and Table 2. As shown in Fig. 9A and B, three decomposition peaks for WPU and all WPU/Ag nanocomposite films were observed. In the first stage, the mass loss for the pristine WPU and WPU/Ag nanocomposite films was attributed to the degradation of residual water and oligomers. ${ }^{27}$ After the temperature higher than $300{ }^{\circ} \mathrm{C}$, the decomposition of urethane hard segments took place. At the last stage with the temperature increasing from 350 to $500{ }^{\circ} \mathrm{C}$, the mass loss was assigned to the dissociation of the soft segments. The effects of incorporation of AgNPs on thermal decomposition behaviors of WPU films could be apparently observed at stage II and stage III, and the degradation temperature of WPU film increased with the incorporation of AgNPs. The reason may be due to the formed AgNPs in polymer matrix restricting the polymer chain mobility and serving as nucleation sites to facilitate the crystallization of WPU, thus better thermal stability. The initial decomposition temperature ( $\left.T_{\text {onset }}\right)$, temperature that corresponds to the maximum rate of decomposition $\left(T_{\max }\right)$ and endset temperature of thermal degradation $\left(T_{\text {endset }}\right)$ of all the WPU/Ag nanocomposite films were 
Table 2 Thermal degradation parameters derived from TGA and DTG curves $^{a}$

\begin{tabular}{|c|c|c|c|c|c|}
\hline Sample & Stage & $T_{\text {onset }}\left({ }^{\circ} \mathrm{C}\right)$ & $T_{\max }\left({ }^{\circ} \mathrm{C}\right)$ & $T_{\text {endset }}\left({ }^{\circ} \mathrm{C}\right)$ & $W_{\text {rez }}(\%)$ \\
\hline \multirow[t]{3}{*}{ WPU } & I & 240.7 & 294.0 & 299.8 & \multirow[t]{3}{*}{1.07} \\
\hline & II & 301.6 & 330.7 & 354.2 & \\
\hline & III & 359.5 & 417.7 & 467.1 & \\
\hline \multirow[t]{3}{*}{ WPU/Ag-1 } & I & 205.7 & 285.6 & 287.1 & \multirow[t]{3}{*}{4.63} \\
\hline & II & 301.1 & 337.52 & 368.5 & \\
\hline & III & 373.7 & 451.9 & 504.3 & \\
\hline \multirow[t]{3}{*}{ WPU/Ag-2 } & I & 220.9 & 286.4 & 296.3 & \multirow[t]{3}{*}{5.19} \\
\hline & II & 305.1 & 349.8 & 379.5 & \\
\hline & III & 386.0 & 457.2 & 508.6 & \\
\hline \multirow[t]{3}{*}{ WPU/Ag-3 } & I & 225.4 & 287.9 & 297.8 & \multirow[t]{3}{*}{4.84} \\
\hline & II & 309.6 & 356.3 & 388.2 & \\
\hline & III & 393.2 & 458.1 & 511.4 & \\
\hline \multirow[t]{3}{*}{ WPU/Ag-4 } & I & 227.1 & 296.2 & 303.1 & \multirow[t]{3}{*}{5.21} \\
\hline & II & 311.2 & 358.3 & 388.5 & \\
\hline & III & 393.8 & 458.6 & 516.8 & \\
\hline
\end{tabular}

${ }^{a} T_{\text {onset }}$ : onset temperature of thermal degradation; $T_{\text {max }}$ : temperature that corresponds to the maximum rate of decomposition for each stage evaluated from the peaks of the DTG curves; $T_{\text {endset }}$ : endset temperature of thermal degradation. $W_{\text {rez }}$ : percentage of residue remained at the end of thermal degradation $\left(700^{\circ} \mathrm{C}\right)$.

Table 3 Temperature values corresponding to different weight losses for all studied samples ${ }^{a}$

\begin{tabular}{llllll}
\hline Sample & $T_{10 \%}\left({ }^{\circ} \mathrm{C}\right)$ & $T_{20 \%}\left({ }^{\circ} \mathrm{C}\right)$ & $T_{30 \%}\left({ }^{\circ} \mathrm{C}\right)$ & $T_{40 \%}\left({ }^{\circ} \mathrm{C}\right)$ & $T_{50 \%}\left({ }^{\circ} \mathrm{C}\right)$ \\
\hline WPU & 295.2 & 324.5 & 354.8 & 391.9 & 402.2 \\
WPU/Ag-1 & 264.1 & 321.5 & 362.7 & 419.4 & 435.8 \\
WPU/Ag-2 & 288.9 & 343.2 & 382.7 & 426.6 & 441.6 \\
WPU/Ag-3 & 309.3 & 354.5 & 392.6 & 428.7 & 442.3 \\
WPU/Ag-4 & 315.8 & 355.4 & 399.4 & 429.9 & 442.9
\end{tabular}

${ }^{a} T_{10 \%}$ : temperature at $30 \%$ mass loss; $T_{20 \%}$ : temperature at $30 \%$ mass loss; $T_{30 \%}$ : temperature at $30 \%$ mass loss; $T_{40 \%}$ : temperature at $40 \%$ mass loss; $T_{50 \%}$ : temperature at $50 \%$ mass loss.

higher than that of the WPU at stage II and stage III. And the $T_{\text {onset }}, T_{\max }$, and $T_{\text {endset }}$ of WPU/Ag nanocomposite films increased with the added mass of $\mathrm{AgNO}_{3}$. The amount of residue $\left(W_{\text {rez }}\right)$ of WPU/AgNPs composites increased due to AgNPs incorporation but several chemical reactions occurred during thermal degradation which may lead to more or less volatile and solid compounds. ${ }^{28}$ And the temperature values corresponding to different weight losses for all the studied samples are represented in Table 3. The results indicate that the corporation of AgNPs in WPU improved the thermal stability of WPU film.

\section{Mechanical properties}

It has been previously reported that incorporation of AgNPs into WPUs could enhance the mechanical properties of WPUs significantly. ${ }^{29}$ Herein, to study the influence of AgNPs on the mechanical properties of the films, the Young's modulus, tensile strength and elongation at break of the WPU and WPU/Ag nanocomposite films were measured (Fig. 10A, B and Table 4). And their stress-strain curves are also shown in Fig. 10C. The
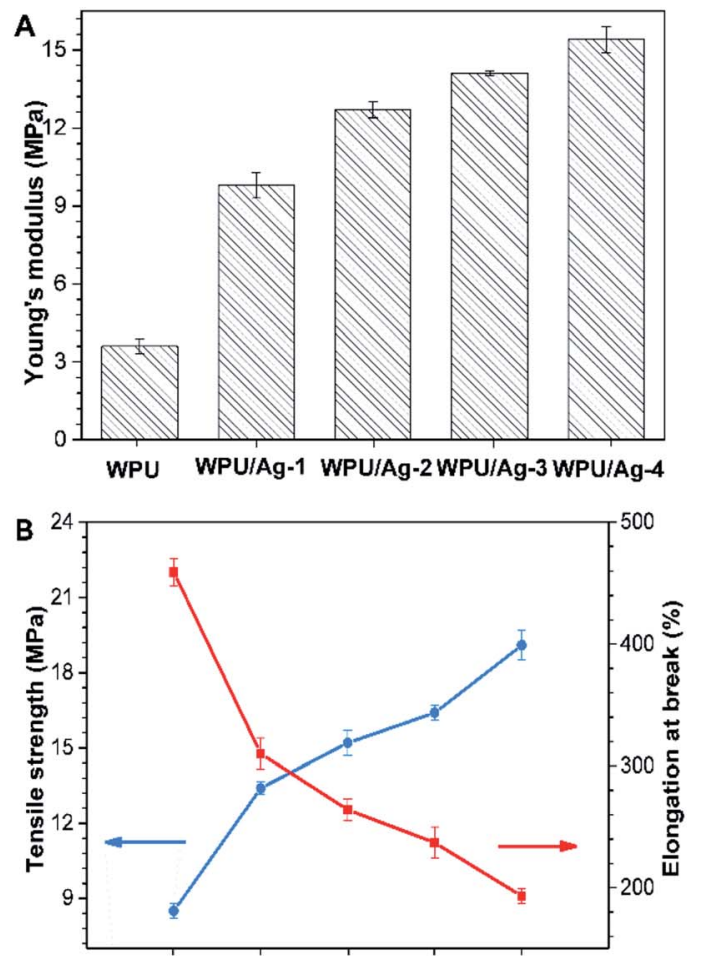

WPU WPU/Ag-1 WPU/Ag-2 WPU/Ag-3 WPU/Ag-4

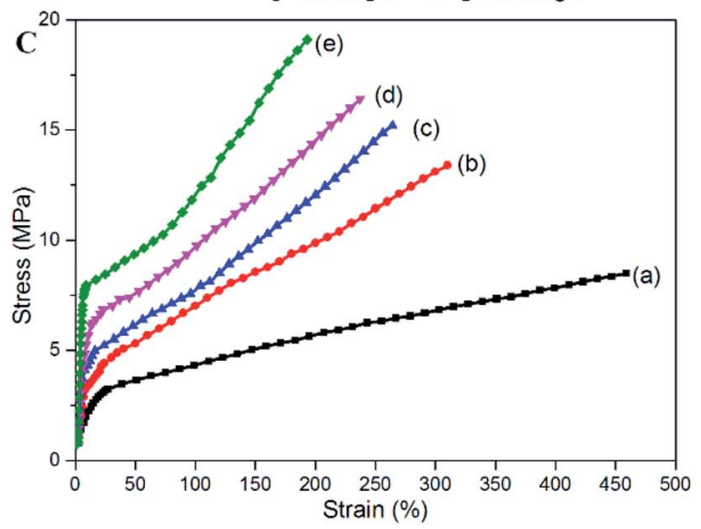

Fig. 10 (A) Young's modulus, (B) tensile strength and elongation at break of the WPU and WPU/Ag nanocomposite films (C) stress-strain curves of (a) WPU, (b) WPU/Ag-1, (c) WPU/Ag-2, (d) WPU/Ag-3 and (e) WPU/Ag-4.

Young's modulus, tensile strength and elongation at break of WPU films were 3.6 MPa, 8.5 MPa and 459\%, respectively, indicating the flexibility of the WPU. After the incorporation of

Table 4 The mechanical properties of the WPU and WPU/Ag nanocomposite films

\begin{tabular}{lccl}
\hline Sample & $\begin{array}{l}\text { Young's } \\
\text { modulus }(\mathrm{MPa})\end{array}$ & $\begin{array}{l}\text { Tensile strength } \\
(\mathrm{MPa})\end{array}$ & $\begin{array}{l}\text { Elongation at } \\
\text { break }(\%)\end{array}$ \\
\hline WPU & $3.6 \pm 0.3$ & $8.5 \pm 0.3$ & $459 \pm 11$ \\
WPU/Ag-1 & $9.8 \pm 0.5$ & $13.4 \pm 0.2$ & $310 \pm 13$ \\
WPU/Ag-2 & $12.7 \pm 0.3$ & $15.2 \pm 0.5$ & $264 \pm 9$ \\
WPU/Ag-3 & $14.1 \pm 0.1$ & $16.4 \pm 0.3$ & $237 \pm 13$ \\
WPU/Ag-4 & $15.4 \pm 0.5$ & $19.1 \pm 0.6$ & $193 \pm 6$
\end{tabular}




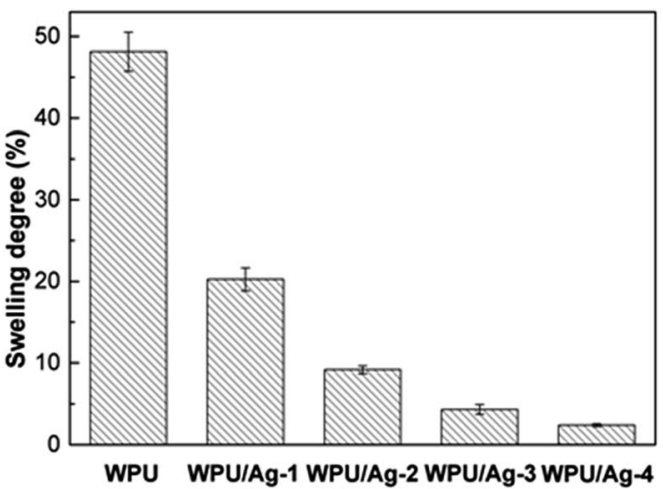

Fig. 11 Swelling degree of the WPU and WPU/Ag nanocomposite films.

Table 5 Antibacterial activity of WPU and WPU/AgNPs films

\begin{tabular}{lll}
\hline Sample & Number & Antibacterial ratio $(\%)$ \\
\hline WPU & $1.97 \times 10^{7}$ & - \\
WPU/Ag-1 & $2.68 \times 10^{6}$ & 86.4 \\
WPU/Ag-2 & $6.8 \times 10^{5}$ & 96.54 \\
WPU/Ag-3 & $2.14 \times 10^{4}$ & 99.89 \\
WPU/Ag-4 & None & 100
\end{tabular}

AgNPs, both Young's modulus and tensile strength increased. With an increase of $\mathrm{Ag}$ content from WPU to WPU/Ag-4, the Young's modulus increased from 3.6 MPa to $15.4 \mathrm{MPa}$, and the tensile strength increased from 8.5 MPa to 19.1 MPa. Both of these intensifications can be ascribed to the interfacial interaction between AgNPs and the polymer matrix, which carries the load from the polymer matrix to the nanofillers. In addition, the hydrogen interaction existed between AgNPs and the - $\mathrm{NH}$ groups in WPU may improve the development in the cross-linking density. The well-dispersed AgNPs in WPU matrix restricted the mobility of the chain segment of WPU, and the interfacial interaction between AgNPs and WPU matrix enabled the material to withstand higher stresses without deforming, making the material stronger. ${ }^{30}$ Besides, the metal-organic complexation effect of AgNPs may be another reason for the enhancement in mechanical properties. ${ }^{31}$ Meanwhile, unfortunately, the elongation at break decreased, indicating the compromise of the flexibility and ductility of film materials. An enhanced cross-linking density enhances the tensile strength but drops the elongation at break. ${ }^{32}$ The decrease in elongation at break may due to the increased cross-linking density of WPU/AgNPs nanocomposites and the rigid nanofillers, which confined the molecular motion of WPU.

\section{Water resistance properties}

The water resistance properties of the WPU and WPU/Ag nanocomposite films were assessed by testing their swelling degree. As shown in Fig. 11, the swelling degree of pristine WPU film was $48.24 \%$. After the incorporation of AgNPs, the swelling degree significantly decreased, and the swelling degree of WPU/ $\mathrm{Ag}-4$ nanocomposite film is only $2.4 \%$. The improvement of the anti-swelling property is probably attributed to the generated dipolar bonds between $\mathrm{Ag}^{+}$and the groups such as $-\mathrm{NH}$ and -COO- in WPU. These findings demonstrate that the incorporation of AgNPs is very beneficial for improving the water resistance property of WPU films.

\section{Antibacterial activity of WPU and WPU/Ag nanocomposite films}

The antibacterial activity of WPU and WPU/AgNPs films with various concentration of silver ions was tested according to ASTM E-2149. The results were presented in Table 5 and Fig. 12. From the results, it can be seen that the pristine WPU film did not exhibit an inhibition for the bacterial growth, while the numbers of live E. coli after incubation with the WPU/AgNPs-1 film, WPU/AgNPs-2 film, WPU/AgNPs-3 film and WPU/AgNPs4 film decreased by $86.4 \%, 96.54 \%, 99.89 \%$ and $100 \%$, respectively, confirming the excellent antibacterial properties of WPU/ AgNPs films. Previous studies have demonstrated the antibacterial activity of AgNPs worked through free release of silver ions killing mechanism and therefore the excellent antibacterial behavior of WPU/AgNPs films was mainly ascribed to the free released silver ions from AgNPs. ${ }^{33}$ Our results indicated that in situ formed AgNPs on the WPUs could work as an immediate source of silver ions to suppress subsequent proliferation of bacteria effectively and sustainably.

\section{Conclusions}

A series of WPU/Ag nanocomposites were successfully prepared via in situ formation of AgNPs in WPUs matrix. Anionic carboxylate-functionalized WPU was synthesized and employed as stabilizers for the synthesis of AgNPs. The prepared WPU and WPU/Ag nanocomposites were characterized by FTIR, UV-vis spectra, TEM, SEM and XRD. The results showed that the formed AgNPs with spherical shape distributed in the WPU matrix evenly and showed good stability without agglomeration
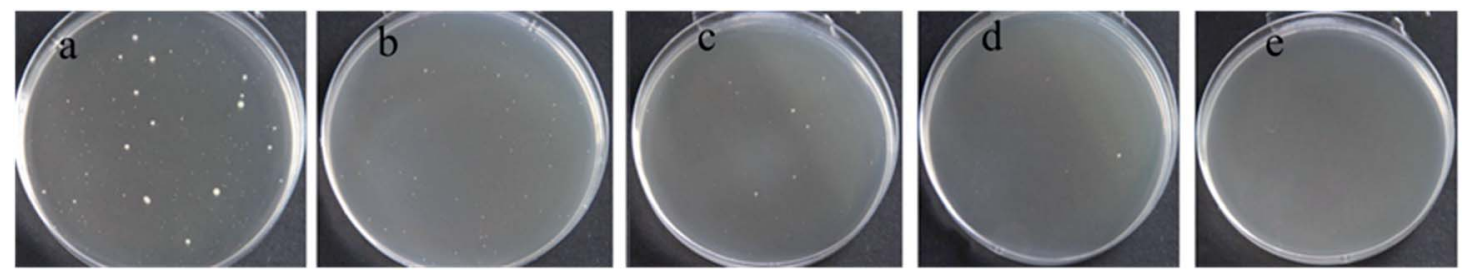

Fig. 12 Pictures of survival bacteria colonies after $48 \mathrm{~h}$ contact, (a) WPU, (b) WPU/Ag-1, (c) WPU/Ag-2, (d) WPU/Ag-3, and (e) WPU/Ag-4. 
after three months. The diameters of AgNPs ranged from 5 to $50 \mathrm{~nm}$ depending on the added amount of silver ions in WPU dispersions. Incorporation of AgNPs in WPU matrix plays an important role in improving the thermal stability, mechanical performance, and water resistance property of WPU films. Furthermore, the presence of AgNPs provided the nanocomposite films with excellent antibacterial behavior against E. coli. All these findings suggest that the developed WPU/Ag nanocomposites could be suitable for a broad range of commercial applications.

\section{Conflicts of interest}

There are no conflicts to declare.

\section{Acknowledgements}

This work was supported by the National Natural Science Foundation of China (No. 81571801), the Fundamental Research Funds for the Central Universities and the Open Funds for Characterization of Tongji University.

\section{References}

1 H. W. Engels, H. G. Pirkl, R. Albers, R. W. Albach, J. Krause, A. Hoffmann, H. Casselmann and J. Dormish, Angew. Chem., Int. Ed., 2013, 52, 9422-9441.

2 X. Zhou, C. Q. Fang, W. Q. Lei, J. Su, L. Li and Y. Li, Prog. Org. Coat., 2017, 104, 1-10.

3 J. Zhao, T. Zhou, J. H. Zhang, H. M. Chen, C. Y. Yuan, W. D. Zhang and A. M. Zhang, Ind. Eng. Chem. Res., 2014, 53, 19257-19264.

4 Q. Wu and J. L. Hu, Composites, Part B, 2016, 107, 59-66.

5 Y. Wu, Z. L. Du, H. B. Wang and X. Cheng, J. Appl. Polym. Sci., 2016, 133, 43949.

6 M. M. Rahman, M. H. Zahir and H. D. Kim, Polymers, 2016, 8, 318.

7 M. M. A. Nikje and Z. M. Tehrani, Polym.-Plast. Technol. Eng., 2010, 49, 812-817.

8 H. F. Zhou, H. Wang, K. Zheng and Q. T. Cheng, Polym. Compos., 2014, 35, 1169-1175.

9 L. Q. Peng, L. C. Zhou, Y. F. Li, F. Pan and S. D. Zhang, Compos. Sci. Technol., 2011, 71, 1280-1285.

10 S. M. Cakić, I. S. Ristić, M. M. Cincović, D. T. Stojiljković and J. B. Simendić, Int. J. Adhes. Adhes., 2016, 70, 329-341.

11 S. Hendessia, E. B. Sevinisa, S. Unalb, F. C. Cebeci, Y. Z. Menceloglua and H. Unalb, Prog. Org. Coat., 2016, 101, 253-261.
12 X. Y. Gao, Y. C. Zhu, S. Zhou, W. Gao, Z. C. Wang and B. Zhou, Colloids Surf., A, 2011, 377, 312-317.

13 Y. L. Su, L. L. Zhao, F. C. Meng, Q. X. Wang, Y. C. Yao and J. B. Luo, Colloids Surf., B, 2017, 152, 238-244.

14 H. M. M. Ibrahim and M. S. Hassan, Carbohydr. Polym., 2016, 151, 841-850.

15 Y. Wattanodorn, R. Jenkan, P. Atorngitjawat and S. Wirasate, Polym. Test., 2014, 40, 163-169.

16 M. Akbarian, M. E. Olya, M. Ataeefard and M. Mahdavian, Prog. Org. Coat., 2012, 75, 344-348.

17 M. A. Pérez-Limiñana, F. Arán-Aís and C. Orgilés-Barceló, J. Adhes., 2014, 90, 860-876.

18 W. Pongnop, K. Sombatsompop, A. Kositchaiyong and N. Sombatsompop, J. Appl. Polym. Sci., 2011, 122, 3456-3465.

19 G. M. Chen, Y. M. Ma, X. J. Zheng, G. Y. Xu, J. Liu, J. Fan, D. Y. Shen and Z. N. Qi, J. Polym. Sci., Part B: Polym. Phys., 2007, 45, 654-660.

20 T. Gurunathan and J. S. Chung, ACS Sustainable Chem. Eng., 2016, 4, 4645-4653.

21 G. Garcia, R. Buonsanti, E. L. Runnerstrom, R. J. Mendelsberg, A. Llordes, A. Anders and D. J. Milliron, Nano Lett., 2011, 11, 4415-4420.

22 S. A. Khan, D. Senapati, T. Senapati, P. Bonifassi, Z. Fan, A. K. Singh, A. Neeley, G. Hill and P. C. Ray, Chem. Phys. Lett., 2011, 512, 92-95.

23 L. L. Lazarus, C. T. Riche, N. Malmstadt and R. L. Brutchey, Langmuir, 2012, 28, 15987-15993.

24 Z. L. Zhang and H. Y. Zhang, RSC Adv., 2015, 5, 17931-14937.

25 Z. Lei, X. Wei, L. Zhang and S. Bi, Colloids Surf., A, 2008, 317, 705-710.

26 Y. Xiao, L. Jiang, Z. M. Liu, Y. Yuan, P. Y. Yan, C. L. Zhou and J. X. Lei, Polym. Test., 2017, 60, 160-165.

27 A. P. Isfahani, B. Ghalei, R. Bagheri, Y. Kinoshita, H. Kitagawa, E. Sivaniah and M. Sadeghi, J. Membr. Sci., 2016, 513, 58-66.

28 H. Q. Fu, Y. Wang, X. Y. Li and W. F. Chen, Compos. Sci. Technol., 2016, 126, 86-93.

29 W. S. Han, Polym. Compos., 2013, 34, 156-163.

30 C. H. Tsou, H. T. Lee, W. S. Huang, M. D. Guzman, S. T. Chen, M. C. Suen and S. T. Wicaksono, Polym. Bull., 2017, 74, 1121-1143.

31 Z. L. Zhang and H. Y. Zhang, RSC Adv., 2015, 5, 17931-17937. 32 S. Choi, K. M. Lee and C. D. Han, Macromolecules, 2004, 37, 7649-7662.

33 H. Liu, J. Song, S. Shang, Z. Song and D. Wang, ACS Appl. Mater. Interfaces, 2012, 4, 2413-2419. 